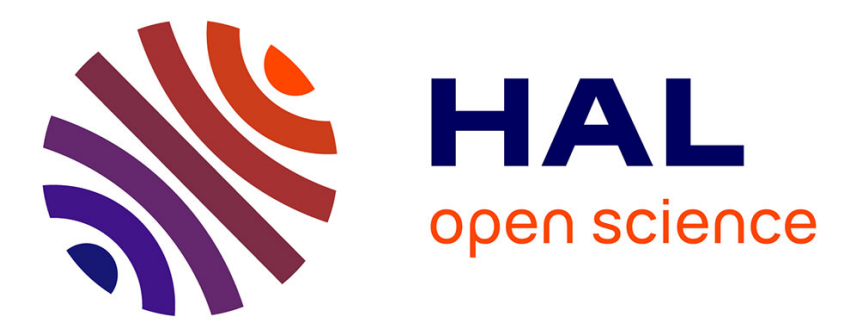

\title{
Gram-type differentiation of bacteria with 2D hollow photonic crystal cavities
}

R. Therisod, M. Tardif, P. R. Marcoux, E. Picard, J.-B. Jager, E. Hadji, D. Peyrade, R. Houdré

\section{> To cite this version:}

R. Therisod, M. Tardif, P. R. Marcoux, E. Picard, J.-B. Jager, et al.. Gram-type differentiation of bacteria with 2D hollow photonic crystal cavities. Applied Physics Letters, 2018, 113 (11), pp.111101. $10.1063 / 1.5037849$. cea-01988778

\section{HAL Id: cea-01988778 https://hal-cea.archives-ouvertes.fr/cea-01988778}

Submitted on 22 Jan 2019

HAL is a multi-disciplinary open access archive for the deposit and dissemination of scientific research documents, whether they are published or not. The documents may come from teaching and research institutions in France or abroad, or from public or private research centers.
L'archive ouverte pluridisciplinaire HAL, est destinée au dépôt et à la diffusion de documents scientifiques de niveau recherche, publiés ou non, émanant des établissements d'enseignement et de recherche français ou étrangers, des laboratoires publics ou privés. 


\section{Gram-type differentiation of bacteria with 2D hollow photonic crystal cavities}

R. Therisod, M. Tardif, P. R. Marcoux, E. Picard, J.-B. Jager, E. Hadji, D. Peyrade, and R. Houdré

Citation: Appl. Phys. Lett. 113, 111101 (2018); doi: 10.1063/1.5037849

View online: https://doi.org/10.1063/1.5037849

View Table of Contents: http://aip.scitation.org/toc/apl/113/11

Published by the American Institute of Physics

\section{Conference Proceedings} print proceedings! 


\title{
Gram-type differentiation of bacteria with 2D hollow photonic crystal cavities
}

\author{
R. Therisod, ${ }^{1, a)}$ M. Tardif, ${ }^{2,3}$ P. R. Marcoux, ${ }^{4}$ E. Picard, ${ }^{3}$ J.-B. Jager, ${ }^{3}$ E. Hadji, ${ }^{3}$ D. Peyrade, ${ }^{2}$ \\ and R. Houdré ${ }^{1}$ \\ ${ }^{1}$ École Polytechnique Fédérale de Lausanne (EPFL), Institut de Physique, Station 3, CH-1015 Lausanne, \\ Switzerland \\ ${ }^{2}$ University Grenoble Alpes CNRS, LTM-Micro and Nanotechnologies for Health, 38054 Grenoble Cedex 9 , \\ France \\ ${ }^{3}$ University Grenoble Alpes, CEA, INAC, PHELIQS, Laboratoire SINAPS, F-38000 Grenoble Cedex 9, France \\ ${ }^{4}$ University Grenoble Alpes, CEA, LETI, Minatec-Campus, 17 Avenue des Martyrs, 38054 Grenoble Cedex 9 , \\ France
}

(Received 28 April 2018; accepted 16 August 2018; published online 10 September 2018)

\begin{abstract}
Fast and label-free techniques to analyze viruses and bacteria are of crucial interest in biological and bio-medical applications. For this purpose, optofluidic systems based on the integration of photonic structures with microfluidic layers were shown to be promising tools for biological analysis, thanks to their small footprint and to their ability to manipulate objects using low powers. In this letter, we report on the optical trapping of living bacteria in a 2D silicon hollow photonic crystal cavity. This structure allows for the Gram-type differentiation of bacteria at the single cell scale, in a fast, label-free, and non-destructive way. (C) 2018 Author(s). All article content, except where otherwise noted, is licensed under a Creative Commons Attribution (CC BY) license (http:// creativecommons.org/licenses/by/4.0/). https://doi.org/10.1063/1.5037849
\end{abstract}

During the last decade, optical resonators integrated with microfluidic layers arose as suitable structures for biological analysis, ${ }^{1}$ thanks to their small footprint and especially thanks to their ability to trap objects with low powers, ${ }^{2-5}$ below the damage threshold of biological entities. The trapping of biomolecules, ${ }^{6-8}$ viruses, ${ }^{9}$ and bacteria ${ }^{10,11}$ was reported. Moreover, the resonant nature of the optical cavities allows for the simultaneous acquisition of information on the trapped object such as size, refractive index, and morphology, thanks to a feedback effect induced by the trapped specimen on the trapping field itself. ${ }^{11-17}$ In parallel, the massive and inappropriate use of antibiotics since the 1950 s has led to antimicrobial resistance. ${ }^{18}$ Because of multidrug resistant pathogens, in a near future, common infections and minor injuries could kill once again. This misuse of antibiotherapy is partly due to long, compelling, and/or expensive diagnostic tools. A complete diagnosis indeed involves several tests, as both identification and antibiotic susceptibility testing are carried out on the pathogen. For this reason, analysis methods are often based on a large number of bacteria, obtained after a time-consuming culture step. ${ }^{19}$ To overcome this problem, the study of nondestructive techniques is of crucial interest, as they could allow for performing the entire set of tests on the same few cells. Currently, the first test performed in the hospital environment is the Gram staining procedure of the specimen under study, so as to yield a very first characterization of the pathogen to be identified. $^{20-22}$ This differential staining consists of a sequence of steps (staining, decolorization, and counterstaining) and allows for the classification of bacteria into two groups, Gram-positive and Gram-negative, depending on the chemical and physical properties of the cell wall. ${ }^{23,24}$ This first identification is used to guide initial therapy, as

${ }^{\text {a)} E-m a i l: ~ r i t a . t h e r i s o d @ e p f l . c h ~}$
Gram-positive and Gram-negative bacteria differ in their susceptibility to various antibiotics. ${ }^{20,21}$ The Gram staining method is widely used, ${ }^{25}$ but it is a restrictive and destructive technique that requires toxic and carcinogenic chemicals. ${ }^{26}$ Other Gram-type identification techniques were suggested, based on $\mathrm{KOH}$ for marine bacteria, ${ }^{27}$ on pyrolysis-mass spectrometry, ${ }^{28}$ or on the reaction between polymyxin $\mathrm{B}$ and lipolysaccharides. ${ }^{29}$ Gram negative bacteria were also identified through a functionalized porous silicon microcavity detecting lipolysaccharides. ${ }^{30}$

Here, we propose a method based on resonant trapping in a $2 \mathrm{D}$ hollow photonic crystal $(\mathrm{PhC})$ cavity. With this structure, we implemented a fast, label-free, and nondestructive technique to distinguish the Gram-type of bacteria at the single-cell level.

The photonic crystal structures are fabricated on siliconon-insulator substrates with conventional electron beam lithography techniques and inductively coupled plasma etching. ${ }^{12,31,32}$ The silica sacrificial layer is then removed via wet etching. The PhC cavity is designed to have a resonant frequency around $1550 \mathrm{~nm}$ and is evanescently excited via a W1 waveguide in an end-fire setup. The lattice holes measure $250 \mathrm{~nm}$ in diameter and they are hexagonally arranged with a lattice constant of $420 \mathrm{~nm}$; the defect hole is $700 \mathrm{~nm}$ in diameter. More details on the photonic crystal cavity can be found in Ref. 12. The entire set of measurements was performed on the same optical cavity, featuring a $Q$ factor of 4500 in water.

To enable the transport of bacteria in the vicinity of the $\mathrm{PhC}$ structures, a polydimethylsiloxane (PDMS) frame (100 $\mu \mathrm{m}$ in thickness) is placed on the sample, and it acts as a container for a drop of the bacteria suspension in deionized water. A glass coverslip, $170 \mu \mathrm{m}$ thick, is then attached to avoid evaporation. Light from a tunable laser is injected with a polarization maintaining lensed fiber, and the transmitted power through the waveguide is collected with a microscope 
objective and detected by a photodiode. A visible camera placed on the top of the sample allows for imaging and visual checking of the trapping events. The device and the optical structure we developed are shown in Fig. 1(a).

The bacteria that were investigated are shown in Fig. 1(b): Escherichia coli (ATCC 11775), Yersinia ruckeri (ATCC 29473), Pseudomonas putida (ATCC 31483), Neisseria sicca (ATCC 29193), Staphylococcus epidermidis (ATCC 12228), Bacillus subtilis (ATCC 11774), and Listeria innocua (ATCC 33090). These strains were chosen as they are all classified as nonpathogenic (biosafety level 1) but are biologically close to pathogen species of importance in the clinical field. For example, L. innocua and $Y$. ruckeri are close to L. monocytogenes and $Y$. enterocolitica, respectively. Bacteria strains were obtained from KwikStik lyophilized reference strains (Microbiologics, St. Cloud, MN). They are grown on an agar medium (COS or TSA, bioMérieux). After $24 \mathrm{~h}$ of incubation $\left(37^{\circ} \mathrm{C}\right.$ ), a suspension of $3 \mathrm{McF}$ (Densimat, BioMerieux) is prepared in an API Suspension medium (bioMerieux). This corresponds to a bacterial concentration of $2.10^{9} \mathrm{cfu} / \mathrm{ml}$ for the Gram-negative rods such as $E$. coli or $P$. putida. The different types of bacteria were selected so that each of the four main pathogen categories (Gram-positive cocci, Gram-positive bacilli, Gram-negative cocci, and Gram-negative bacilli) included at least one strain. E. coli, Y. ruckeri, and P. putida are Gram-negative bacilli, whereas $N$. sicca is a Gram- negative coccus. S. epidermidis is a Gram-positive coccus, whereas $B$. subtilis and L. innocua are Gram positive bacilli.

The differences in the cell wall composition outlined by the differential Gram staining are shown in Fig. 1(c): Grampositive bacteria show a plasma membrane surrounded by a thick (20-80 nm) peptidoglycan layer, while Gram-negative ones exhibit two membranes separated by a periplasmic space $(30-70 \mathrm{~nm}$ thick) containing a thinner $(5-10 \mathrm{~nm})$ peptidoglycan layer. Moreover, Gram - cell wall presents large molecules, the lipopolysaccharides (LPSs), which project from the outer membrane. Regarding the morphology, $N$. sicca and S. epidermidis are classified as cocci: they have an oval shape and they aggregate in diplococci resulting in a size from $0.5 \times 1 \mu \mathrm{m}$ to $1 \times 2 \mu \mathrm{m}$. The other bacteria under analysis are classified as bacilli and they are rod-shaped with different sizes ranging from $1 \times 2 \mu \mathrm{m}$ to $1 \times 3 \mu \mathrm{m}$.

For every type of bacteria, a drop of suspension is inserted in the PDMS frame, allowing for the bacteria to move in Brownian motion and eventually to be trapped, while passing in the vicinity of the excited resonant cavity. Infrared light at the resonance frequency is injected into the input waveguide, and the evanescent coupling between the W1 waveguide and the optical cavity allows for the excitation of the electromagnetic mode supported by the cavity itself. This results in a maximum of the field confined in the resonant cavity and consequently in a minimum of the a)

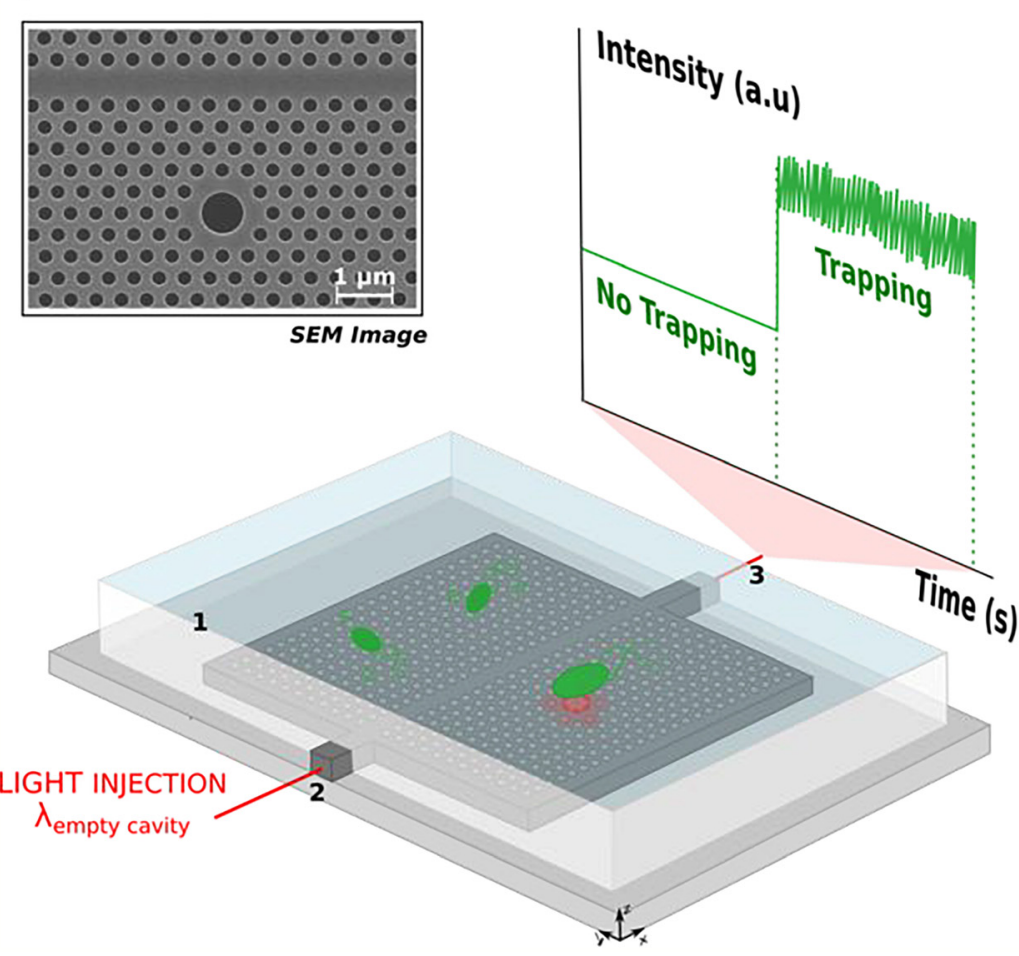

b)

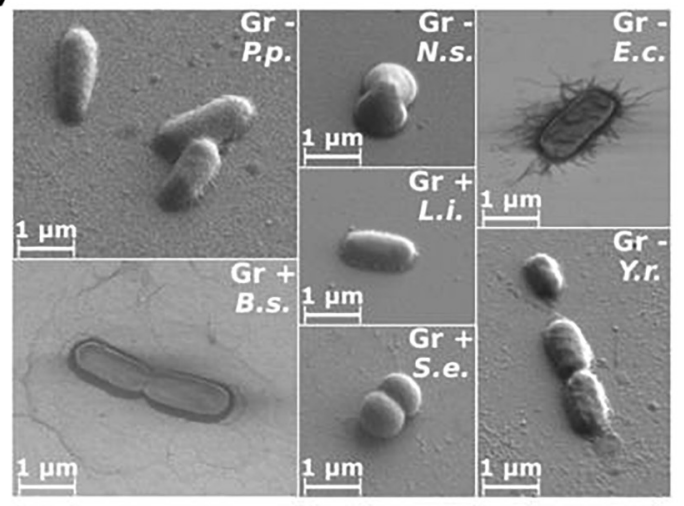

c)

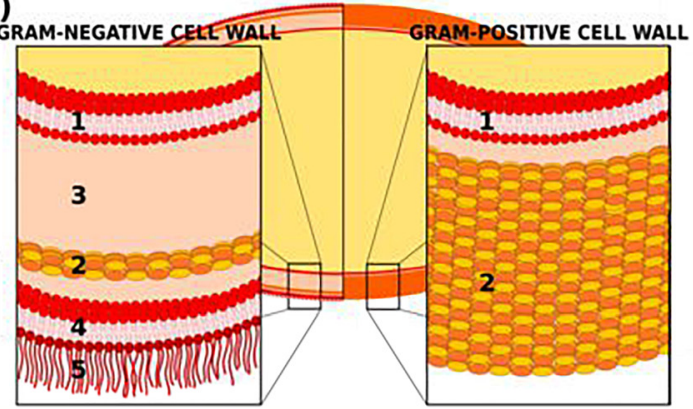

FIG. 1. (a) SEM image of the 2D hollow photonic crystal cavity and experimental setup. The photonic crystal structures are immersed in water (1) thanks to a PDMS frame that allows for the Brownian motion of bacteria in the proximity of the optical cavity. Light from a tunable laser is injected at the resonance wavelength into the access waveguide (2) in an end-fire setup. The transmitted light is collected from the other facet of the sample (3) via a microscope objective and its intensity is monitored with an oscilloscope. (b) SEM pictures of the seven bacteria under study. P.p. stands for Pseudomonas putida, N.s. for Neisseria sicca, E.c. for Escherichia coli, Y.r. for Yersinia ruckeri, B.s. for Bacillus subtilis, L.i. for Listeria innocua, and S.e. for Staphylococcus epidermidis. The Gram-type of these bacteria is also indicated: Gr- for Gram-negative and Gr+ for Gram-positive bacteria. (c) Depiction of the structural differences in the cell wall for Gram-negative and Gram-positive bacteria. Gram- bacteria show two membranes (plasma 1 and outer 4) separated by a liquid periplasmic space (3) and by a thin (5-10 nm) peptidoglycan layer (2). Moreover, lipopolysaccharides (LPSs, 5) project from the outer membrane. On the contrary, Gram + bacteria exhibit a less complex structure, with a single membrane (plasma 1), surrounded by a thick cell envelope (20-80 nm) made of a peptidoglycan layer (2) and no LPSs. 
detected power through the waveguide. When a bacterium is trapped, a variation of the refractive index overlapping with the confined field occurs and this leads to a redshift in the resonance wavelength [Fig. 2(a)]. If the tunable source is kept at the initial wavelength, an increase in the transmission is observed [Fig. 2(b)], which is correlated with the resonance shift and can hence be used to acquire information on the trapped specimen. A laser power of $10 \mathrm{~mW}$ was used to perform the experiment, resulting in an estimated power in the cavity ${ }^{2}$ of the order of hundreds of $\mu \mathrm{W}$.

Typically, trapping events occur after a few seconds from turning on the excitation laser [Fig. 2(b)]. Bacteria are stably trapped over minutes, but a few seconds are sufficient to obtain information. After recording the transmission signal for $5 \mathrm{~s}$, the excitation laser is thus turned off. The bacteria are then free to move by Brownian motion and to step away from the cavity region, while other ones will move in its proximity. The laser is turned on again and a new transmission record is performed.

Additionally, for S. epidermidis (Gram+) and for $P$. putida (Gram-), five measurements were performed to determine the resonance shift corresponding to the transmission increase. A second tunable laser was used as a probe in the following way: the two sources were injected in the waveguide via a $1.55 \mu \mathrm{m} 50 / 50$ fiber-optic coupler. ${ }^{33}$ The first source was kept at the empty cavity resonance wavelength, and it was responsible for the trapping of bacteria. The second one was used to measure the transmission spectrum in the presence of trapped specimen. The comparison between the spectra obtained in the two cases (empty cavity/ trapped bacteria) permits the determination of the induced resonance shift. The mean resonance shift found for S. epidermidis is $0.12 \mathrm{~nm}$, while for P. putida, it is $0.28 \mathrm{~nm}$. In Fig. 2(c) are depicted the minimum shift observed for S. epidermidis $(0.07 \mathrm{~nm})$ and the minimum relative transmission augmentation observed (0.20 in average). In Fig. 2(d), the maximum shift for $P$. putida $(0.31 \mathrm{~nm})$ and the maximum relative transmission increase ( 0.76 in average) are plotted.

The analysis of the transmitted power measured for the seven different bacteria is completed through the calculation of the histogram functions of the transmitted signals. The histograms are calculated for ten trapping events for every bacterial species and normalized to the relative transmission with respect to the empty cavity one for better comparison. A mean histogram is deduced for each bacteria type and is shown in Fig. 3(a).

The results show differences in the FWHM and in the mean value of the histograms: in particular, Gram-negative bacteria (E. coli, P. putida, N. sicca, and Y. ruckeri) exhibit a larger transmission increase with respect to Gram-negative ones (L. innocua, S. epidermidis, and B. subtilis). In Fig. $3(\mathrm{~b})$, the average values of the relative transmission augmentation (corresponding to the peak value of the histogram functions) are plotted for the seven types of bacteria. For every bacterial species, ten measurements $(5 \mathrm{~s}$ long) were considered, to obtain a statistical representation of the response of the population. The measurements were performed over a period of five months, ensuring the reproducibility of the results. Gram-positive bacteria present a relative transmission comprised between 1.15 and 1.37, while for Gram-negative ones, it is comprised between 1.47 and 1.91. A demarcation value appears to be around a relative transmission of 1.40. These transmission ranges are correlated with the resonance wavelength shift of the cavity in the presence of the bacterium (Fig. 2). Indeed, we observed that the shift induced by the trapping of a Gram-positive a)

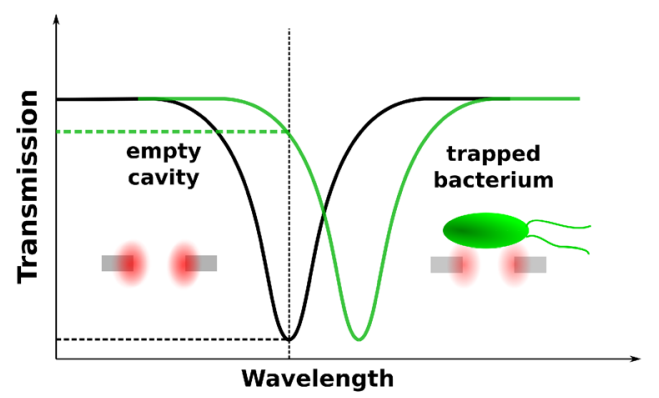

b)

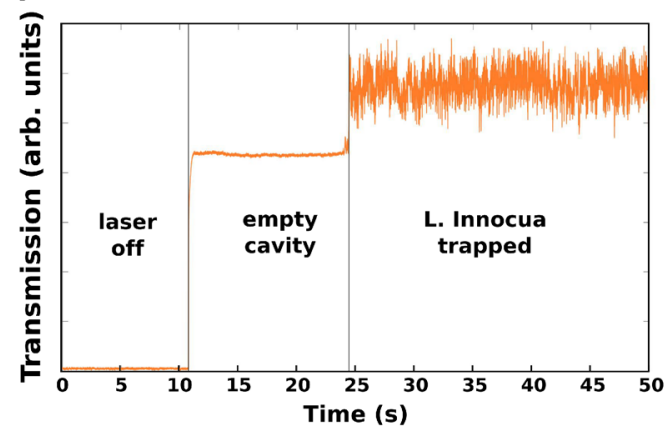

c)
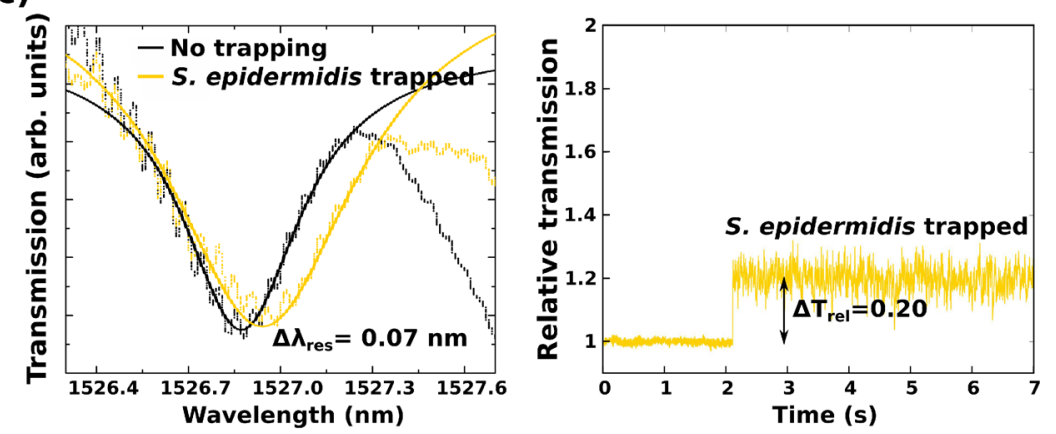

d)
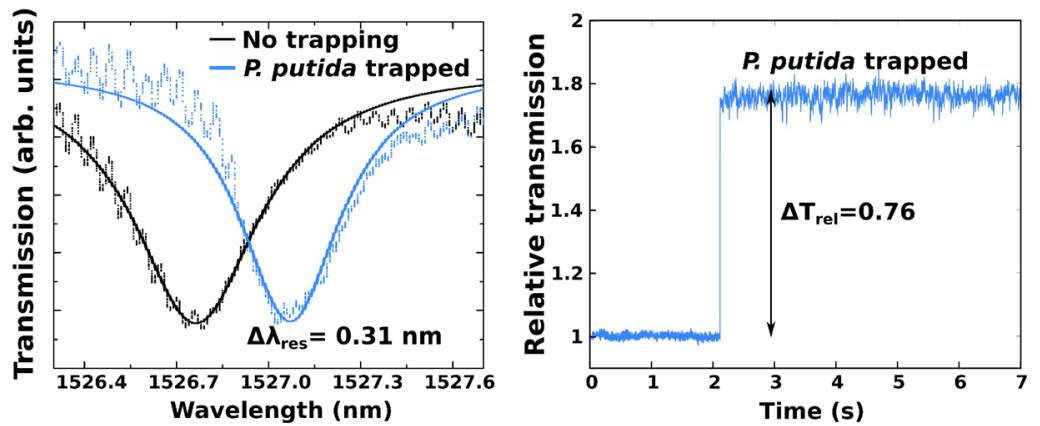

FIG. 2. (a) Representation of the redshift induced in the resonance frequency by a trapped bacterium. (b) Transmission recorded for $L$. innocua. (c) Minimum shift observed for S. epidermidis and minimum relative transmission augmentation. (d) Maximum shift observed for $P$. putida and maximum relative transmission increase. 
a)

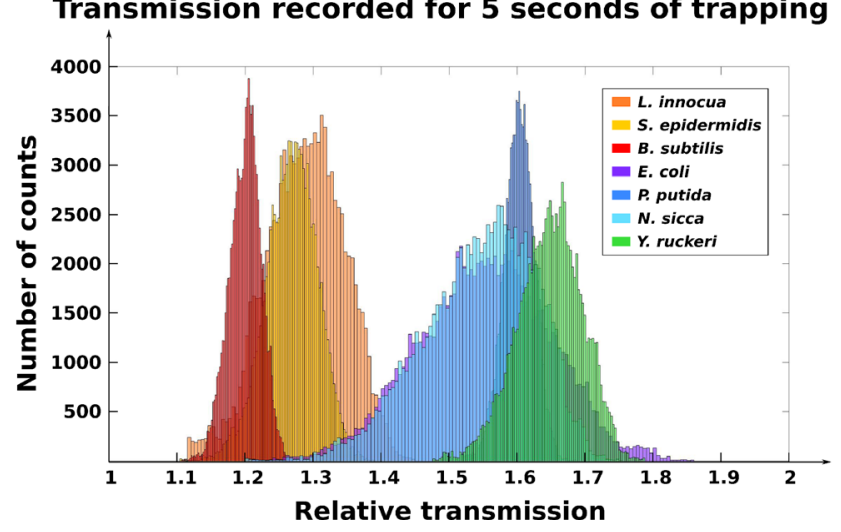

b)

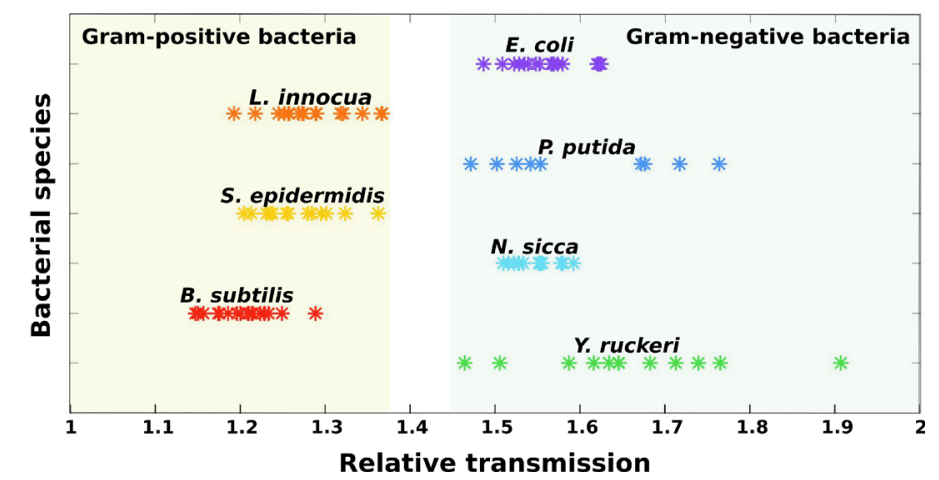

FIG. 3. (a) Histogram functions of the average relative transmission increase over 10 measurements for seven types of bacteria. (b) Mean values of the transmitted power increase for each bacterial species.

bacterium (S. epidermidis, $0.12 \mathrm{~nm}$ ) is under $50 \%$ of the one caused by the trapping of a Gram-negative bacterium ( $P$. putida, $0.28 \mathrm{~nm}$ ). It was previously shown that the resonance shift depends on the refractive index of the trapped specimen and on the overlap with the cavity mode volume. ${ }^{12,33}$ For every bacterial species, a dispersion in the transmission augmentation is present and in some cases it is very large (for instance, for Yersinia ruckeri, the values are comprised between 1.46 and 1.91). Those variations can be explained with several factors: first of all, the intrinsic phenotypic variability of the bacterial population. Second, the orientation, the position with respect to the trapping field, and the size and the shape of the bacteria trapped can impact, as the overlap with the confined field changes accordingly. Moreover, the refractive index of the cell wall may vary.

To have a representative response, which overcomes the differences induced by those parameters, for each Gram stain, at least one bacillus and one coccus was selected. Moreover, differences in the motility of the bacteria studied are present, due to the presence or absence of flagella [Fig. 1(b)]. To take into account the phenotypic variability and the orientation and position effects, ten measurements for each bacterial species were performed. Despite the substantial differences between bacterial species and despite the variability shown for each type of bacteria, Gram-negative bacteria always show a larger shift than Gram-positive ones and the demarcation value around 1.4 of relative transmission is never crossed. On this structure, the differences observed in the transmission increase can thus be explained with the structural differences in the cell wall that differentiate Grampositive and Gram-negative bacteria. In particular, the larger shift induced by Gram-negative bacteria agrees with the greater deformability of the cell wall, ${ }^{34}$ due to the liquid periplasmic space that separates the inner and outer membranes [Fig. 1(c)]. This larger deformability results in a larger overlap with the confined field and hence in a stronger feedback effect. The LPS (lipopolysaccharides) might also be an explanation for the observed differences. These large and complex molecules indeed project from the surface of the outer membrane [4 in Fig. 1(c)] of Gram-negative bacteria but are absent from the cell envelope [2 in Fig. 1(c)] of Gram-positive bacteria.
Furthermore, information on some trapped bacteria can be obtained by combining the relative transmission range with the FWHM of the histogram functions. For instance, it is possible to distinguish $B$. subtilis in the Gram-positive group and $P$. putida in the Gram-negative one, due to the fact that their FWHM is lower than the one of their Gramtype homologue [Fig. 3(a)]. Differences in FWHM are in agreement with previous results on bacteria identification using a SOI 1D microcavity. ${ }^{11}$ The FWHM is linked to the stability of the trapped specimen in the trap, and future work will be performed to provide information on the mobility of the bacteria, such as the presence or absence of flagella.

In conclusion, we report on the optical trapping in a $2 \mathrm{D}$ silicon hollow photonic crystal cavity as a nondestructive characterization method on single cells. This technique is illustrated here on seven species of living bacteria, featuring different morphologies, motilities (presence or absence or flagella), and Gram staining properties. We showed that Gram-type could unambiguously be determined on this set of species, in a fast and label-free way. The system can be integrated into a lab-on-a-chip platform for fast discrimination of Gram-type, allowing for the possibility to use the same cells for further analyses. This possibility is currently prevented because of the destructive nature of the Gram staining procedure. Moreover, it is conceivable to extend this method to Gram-variable and Gram-indeterminate bacteria. The small amount of suspension required, together with the rapidity of a simple transmission measurement [few seconds are sufficient, Fig. 2(b)], make this technique a promising tool for fast, label-free, and non-destructive identification of bacterial species at the single-cell scale.

R.T. and R.H. acknowledge funding from the Swiss National Science Foundation through Project No. 200020_169590.

\footnotetext{
${ }^{1}$ X. Fan and I. M. White, Nat. Photonics 5, 591 (2011).

${ }^{2}$ N. Descharmes, U. P. Dharanipathy, Z. Diao, M. Tonin, and R. Houdré, Phys. Rev. Lett. 110, 123601 (2013).

${ }^{3}$ M. Tonin, F. M. Mor, L. Forró, S. Jeney, and R. Houdré, Appl. Phys. Lett. 109, 241107 (2016).

${ }^{4}$ S. Lin, E. Schonbrun, and K. Crozier, Nano Lett. 10, 2408 (2010).

${ }^{5}$ M. L. Juan, R. Gordon, Y. Pang, F. Eftekhari, and R. Quidant, Nat. Phys. 5, 915 (2009).
} 
${ }^{6}$ S. Mandal, J. M. Goddard, and D. Erickson, Lab Chip 9, 2924 (2009).

${ }^{7}$ M. R. Lee and P. M. Fauchet, Opt. Express 15, 4530 (2007).

${ }^{8}$ H. Zhu, I. M. White, J. D. Suter, P. S. Dale, and X. Fan, Opt. Express 15, 9139 (2007).

${ }^{9}$ P. Kang, P. Schein, X. Serey, D. O’Dell, and D. Erickson, Sci. Rep. 5, 12087 (2015).

${ }^{10}$ T. van Leest and J. Caro, Lab Chip 13, 4358 (2013).

${ }^{11}$ M. Tardif, J. B. Jager, P. R. Marcoux, K. Uchiyamada, E. Picard, E. Hadji, and D. Peyrade, Appl. Phys. Lett. 109, 133510 (2016).

${ }^{12}$ N. Descharmes, U. P. Dharanipathy, Z. Diao, M. Tonin, and R. Houdré, Lab Chip 13, 3268 (2013).

${ }^{13}$ C. F. Carlborg, K. B. Gylfason, A. Kaźmierczak, F. Dortu, M. J. B. Polo, A. M. Catala, G. M. Kresbach, H. Sohlström, T. Moh, L. Vivien, J. Popplewell, G. Ronan, C. A. Barrios, G. Stemme, and W. van der Wijngaart, Lab Chip 10, 281 (2010).

${ }^{14}$ M. G. Scullion, A. Di Falco, and T. F. Krauss, Biosens. Bioelectron. 27, 101 (2011).

${ }^{15}$ O. Levi, M. M. Lee, J. Zhang, V. Lousse, S. R. J. Brueck, S. Fan, and J. S. Harris, Proc. SPIE 6447, 64470P (2007).

${ }^{16}$ A. F. Koenderink, M. Kafesaki, B. C. Buchler, and V. Sandoghdar, Phys. Rev. Lett. 95, 153904 (2005).

${ }^{17}$ L. Neumeier, R. Quidant, and D. E. Chang, New J. Phys. 17, 123008 (2015).

${ }^{18}$ C. L. Ventola, Pharm. Ther. 40, 277 (2015).

${ }^{19}$ P. R. Murray and E. J. Baron, Manual of Clinical Microbiology (ASM Press, Washington, DC, 2007).

${ }^{20}$ A. R. Hauser, Antibiotic Basics for Clinicians: The ABCs of Choosing the Right Antibacterial Agent, 2nd ed. (Lippincott Williams \& Wilkins, 2013).
${ }^{21}$ R. A. Harvey, C. Nau Cornelissen, and B. D. Fisher, Lippincott's Illustrated Reviews: Microbiology, 3rd ed. (Lippincott Williams \& Wilkins, 2013).

${ }^{22}$ W. J. Winn, S. Allen, W. Janda, E. Koneman, G. Procop, P. Schreckenberger, and G. Woods, Koneman's Color Atlas and Textbook of Diagnostic Microbiology, 6th ed. (Lippincott Williams \& Wilkins, 2006).

${ }^{23}$ T. Silhavy, D. Kahne, and S. Walker, Cold Spring Harbor Perspect. Biol. 2, 1 (2010).

${ }^{24}$ J. Willey, L. Sherwood, and C. J. Woolverton, Prescott, Harley \& Klein's Microbiology, 7th ed. (Mc Graw Hill, 2008).

${ }^{25}$ T. J. Beveridge, Biotech. Histochem. 76, 111 (2001).

${ }^{26} \mathrm{~S}$. Mani and R. N. Bharagava, in Reviews of Environmental Contamination and Toxicology, edited by W. P. de Voogt (Springer International Publishing, Cham, 2016), Vol. 237, pp. 71-104.

${ }^{27}$ J. D. Buck, Appl. Environ. Microbiol. 44, 992 (1982).

${ }^{28}$ F. Basile, K. J. Voorhees, and T. L. Hadfield, Appl. Environ. Microbiol. 61, 1534 (1995).

${ }^{29}$ J. Wiegel and L. Quandt, J. Gen. Microbiol. 128, 2261 (1982).

${ }^{30}$ S. Chan, S. R. Horner, P. M. Fauchet, and B. L. Miller, J. Am. Chem. Soc. 123, 11797 (2001).

${ }^{31}$ M. Loncar, T. Doll, J. Vuckovic, and A. Scherer, J. Lightwave Technol. 18, 1402 (2000).

${ }^{32}$ D. Peyrade, Y. Chen, A. Talneau, M. Patrini, M. Galli, F. Marabelli, M. Agio, L. C. Andreani, E. Silberstein, and P. Lalanne, Microelectron. Eng. 61-62, 529 (2002).

${ }^{33}$ M. Tardif, E. Picard, P. R. Marcoux, V. Gaude, J. B. Jager, E. Hadji, and D. Peyrade, "Monitoring bacterial response to heat stress with on-chip optical micro-resonator" (unpublished).

${ }^{34}$ V. Vadillo-Rodriguez, S. R. Schooling, and J. R. Dutcher, J. Bacteriol. 191, 5518 (2009). 